\title{
BMJ Open Prevalence and factors associated with underweight children: a population- based subnational analysis from Pakistan
}

Ramesh Kumar, ${ }^{\oplus 1}$ Faisal Abbas, ${ }^{2,3}$ Tahir Mahmood, ${ }^{2,4}$ Ratana Somrongthong ${ }^{5}$

To cite: Kumar R, Abbas F, Mahmood T, et al. Prevalence and factors associated with underweight children: a population-based subnational analysis from Pakistan. BMJ Open 2019;9:e028972. doi:10.1136/ bmjopen-2019-028972

- Prepublication history for this paper is available online. To view these files, please visit the journal online (http://dx.doi. org/10.1136/bmjopen-2018028972).

Received 8 January 2019

Revised 25 June 2019

Accepted 26 June 2019

D Check for updates

(c) Author(s) (or their employer(s)) 2019. Re-use permitted under CC BY-NC. No commercial re-use. See rights and permissions. Published by BMJ.

${ }^{1}$ Health Systems and Policy Department, Health Services Academy, Islamabad, Pakistan ${ }^{2}$ Department of Economics, George August University, Goettingen, Germany ${ }^{3}$ Independant Researcher, and Development Consultant, Islamabad, Pakistan

${ }^{4}$ Department of Economics, Chitral University, Chitral,

Pakistan

${ }^{5}$ College of Public Health Sciences, Chulalongkorn University, Bangkok, Thailand

Correspondence to Dr Ramesh Kumar; ramesh@hsa.edu.pk, drramesh1978@gmail.com

\section{ABSTRACT}

Objectives This study aims to determine the prevalence of and factors associated with underweight children under the age of 5 in Punjab, Pakistan.

Design We analysed cross-sectional household-level subnationally representative Multiple Indicator Cluster Survey.

Settings Punjab province, Pakistan.

Participants 24042 children under 5 years of age. Data analysis Multilevel multivariate logistic regression analysis.

Results Prevalence of moderately and severely underweight children was found to be $(33.3 \%$ and $11.3 \%$, respectively). Multivariate multilevel logistic regression results show that as the child grows older the likelihood of the child being underweight increases significantly (eg, children between 12 and 23 months are one and half times more likely to be underweight, whereas children between the ages of 36 and 47 months are two and a half times more likely to be underweight). Gender was found to be another significant factor contributing to underweight prevalence among children under the age of 5. The likelihood of a girl child being underweight is more than that of a boy child being underweight (OR 0.92, 95\% $\mathrm{Cl} 0.8$ to 1.0). Similarly, a child whose birth order is three or more is two times more likely to be underweight (OR $1.96,95 \% \mathrm{Cl} 1.5$ to 2.5 ) relative to a child of a lower birth order. Moreover, diarrhoea also significantly increases the likelihood of the child being underweight (OR 1.31, $95 \% \mathrm{Cl} 1.1$ to 1.5). Child size is another determinant for underweight prevalence among children under 5 , for example, a child with a size smaller than average at the time of birth is 2.7 times more likely to be moderately underweight than a child with an average or larger than average size at the time of birth.

Conclusion Rigorous community-based interventions should be developed and executed throughout the province to improve this grave situation of underweight prevalence in Punjab. Mother's education should be uplifted by providing them formal education and providing awareness about the importance of proper nutrition for children.

\section{INTRODUCTION}

With at least $29 \%$ of the children under the age of 5 being underweight in South Asia, the region bears an unfair burden of

\section{Strengths and limitations of this study}

- This study employed a multilevel modelling approach to exploit the household-level and community-level variation which is helpful to formulate better policies.

- Multilevel regression helps in exploring the variation at various levels of hierarchy which is important from a policy prescription perspective.

- A unique aspect of this study is that Multiple Indicator Cluster Survey (Punjab 2014) data provide very rich information at household, community, district and administrative division level that naturally suits employing hierarchical modelling approach.

- Due to the cross-sectional nature of the data, causality cannot be inferred and results cannot be generalised to the national level.

undernutrition. ${ }^{1}$ National Nutrition Survey 2011 shows that $31 \%$ children under 5 years of age are underweight, ${ }^{2}$ while a recent study in Pakistan reported that the current prevalence of underweight children in the country lies at $29 \% .^{3}$ This ratio of underweight children in Pakistan is quite high. It is estimated that one out of every three children under the age of 5 is found to be underweight in Punjab, Pakistan. Punjab province, which is the largest province of Pakistan, has an underweight prevalence which ranges from $33.7 \%$ (moderate) to $11.3 \%$ (severe). This ratio has seen an increase since 2011 when the underweight prevalence among children in the province ranged from $32.6 \%$ (moderate) to $11.2 \%$ (severe). ${ }^{4}$ Consequently, while there has been a decrease in prevalence of underweight in Pakistan over time, the prevalence of underweight children in Punjab province is increasing. This increase in underweight prevalence in one of the largest provinces of the country by population, Gross Domestic Product (GDP) and employment contribution presents a daunting challenge towards achieving the sustainable development goals 
(SDGs) of ending poverty and hunger by 2030 . The reported high prevalence of underweight children in Pakistan remains a big concern for policy makers, ${ }^{5}$ and, thus, requires urgent interventions by the state and the provincial government. ${ }^{6}$ Therefore, it is of critical importance that the factors associated with high prevalence of underweight children in Punjab province of Pakistan are fully understood.

Undernutrition has become a major public health concern, especially in developing countries. This prevalent threat affects around 165 million children under the age of 5 every year and causes 13 million deaths globally during the same period. ${ }^{78}$ Almost half of these deaths caused by undernutrition among children have been reported in Asia alone. ${ }^{9}$ Proper diet is an important determinant which leads to normal growth in children, thus proper attention needs to be given to the food, environment, health and hygiene of children. ${ }^{1011}$

There are many contributing factors which lead to being underweight in children. These include low birth weight of children, poor exclusive breast feeding, discouraged complementary diet, dietary diversity, parent's education, lack of nutrition knowledge, family planning, income status, limited access to adequate food and poor immunisation status. ${ }^{72-14}$ In addition to these, personal hygiene and sanitation can also help reduce underweight children. These changes would result in a decrease in child mortality by $14 \%-31 \%{ }^{14}$ The effect of child malnutrition is very harmful and leads to low physical and cognitive development during childhood and affects educational accomplishment, health status and performance in labour market outcomes during adulthood, while also resulting in $15 \%$ of the total disability. ${ }^{15}$ Thus far, there is limited research evidence available to explore the determinants of undernutrition (underweight) in Pakistan. The studies that have previously been conducted are mostly based on either specific health facilities, ${ }^{1617}$ small sample size ${ }^{18}$ or specific regions with limited covariates ${ }^{19}{ }^{20}$; however, no single research has employed a multilevel model to unravel variations at different levels of hierarchy within the data which can help explain the dynamics and, hence, provide robust results for sound policy formulation and interventions. This analysis investigates the association of being underweight as a dependent variable and maternal and child level characters, socioeconomic, demographic and regional factors. Therefore, the aim of this study is to identify possible interventions and indicator-specific programming that can help address the gap and decrease the incidence of underweight children in Pakistan.

\section{METHODS}

\section{Participants and study settings}

The Multiple Indicator Cluster Survey (MICS) is an international household survey programme developed by the United Nations Children's Fund (Unicef). In Punjab, between June and September 2014, MICS collected household-level data to analyse the health of women and children, while also employing anthropometric (nutrition) measures and education measures among other key indicators. The two-stage stratified cluster sampling MICS data covered rural and urban areas of all 9 divisions and 36 districts of the province. Enumeration Blocks (EB) in urban areas and villages in rural areas were the primary sampling units (PSU). Households were considered as secondary sampling units, and from each PSU, 20 households were selected with a random start. The total sample consisted of 41000 households with a response rate of $98 \%{ }^{4}$

\section{Variables}

Dependent variable in this analysis is underweight. Underweight is moderate if the weight-for-age z-score of a child under 5 years of age is less than $-2 \mathrm{SD}$ from WHO reference growth standards, and it is severe if z-score is less than -3 $\mathrm{SD}^{21}$

Independent variables in this study include age of child in months and is categorised into $0-5$ months, $6-11$ months, 12-23 months, 24-35 months, 36-47 months and 48-59 months. The first year of the child is divided into two categories as during the first 6 months, the child is either exclusively breast fed or has a strictly milk only diet, whereas between 6 and 12 months, solid food is also included in his/her diet. Birth order of the child is a variable which adds a rank to the number of children born to women of ages $15-49$, and is categorised as first born, second born and third or those born after that under 5years of age. Gender of the child is characterised as either boy or girl. Size of child at birth is divided into three categories: large, average and small. Diarrhoea, that is, whether a child had diarrhea in the last two weeks (15 days), is included as a binary variable (Yes=1; 0 otherwise). Breastfeeding is a binary variable, that is, if a child has ever been breast fed $(\mathrm{Yes}=1)$ and $(\mathrm{No}=0)$. Mother and father's education is categorised as no education (less than 1 year), primary ( $1-5$ years completed), middle (6-8 years of education completed), secondary (9-10 years of education completed) and higher (11+ years of education completed, including professional or university degrees). Mother's age is a categorical variable: less than 18 years, $18-24$ years, $25-35$ years and $36+$ years. Postnatal care is included as a proxy, that is, whether a female health worker visited the household in the past 3 months, and it is included as a binary variable. This variable captures the knowledge and information exchange that is positively associated with child health outcomes. Antenatal care visits (ANC visits) include the number of times a woman received antenatal care during pregnancy and are coded as up to four times as recommended by WHO and $4+$ times. Place of delivery, that is, where a woman gives birth to her child, is coded as home delivery if birth occurred at her own home or at another home and institutional delivery if the delivery occurred at either a public or a private hospital or maternity care or basic/primary healthcare centre. Mothers who smoke and gender of parents are also included in the analysis. Household size includes number of household members in a household and is categorised into 3-4 household members, 5-6 household members (which is the average size of a family in Punjab), 7-8 household members 
and more than 8 household members (to capture the effect of a very large family on child health outcomes). Community-level variables include ethnicity, place of residence, sanitation facilities, water facilities and water treatment. Ethnicity is determined according to the head of household's mother tongue and is categorised into Urdu, Punjabi, Saraiki and Others. Place of residence is a binary variable and is coded as $u$ rban $=1$ and rural $=0$. Sanitation facility is determined according to whether the household has access to a toilet facility. It has been divided into two categories based on the WHO definition, ${ }^{22}$ that is, improved sanitation facility, which includes sewer connections, septic system connection, pour flush latrines, ventilated improved pit latrines and pit latrines with a slab or covered pit, and unimproved sanitation facility, which includes spit latrines without slabs or platforms or open pit hanging latrines bucket latrines, open defecation in fields, forests and/or bushes. Water treatment is determined by whether the household treats water to make it safe for drinking and is included as a binary variable coded as treated $=1$ and untreated $=0$. It is also imperative to note here, for the purpose of analysis, that Punjab province is divided into nine administrative divisions (The division is subdivided into many small administrative districts. In total, there are 36 districts in 9 divisions): Rawalpindi, Bahawalpur, D.G. Khan, Faisalabad, Gujranwala, Lahore, Multan, Sahiwal and Sargodha.

\section{Data analysis}

As MICS is a clustered hierarchical household-level data set, thus, to effectively understand the complexities associated with the groups' variability and the effect of group level characteristics on individuals, it is necessary to employ the multilevel modelling approach for the analysis. ${ }^{23-27}$ We used a three-level random intercept multilevel hierarchical model, using MICS 2014 data which consists of 24042 children under the age of 5 , for Punjab province of Pakistan. The analysis has been conducted by associating weights to each household. Numerous methodologies have been used in the literature to interpret variance components at each level of multilevel models. For this analysis, we are using two important approaches. These include variance partition coefficients (VPCs) and intraclass correlation coefficients (ICCs). VPC presents the proportion of the outcome variable variance that lies at each level of the model hierarchy. ICC measures the expected degree of similarity between responses within a specific level. This study is based on an analysis of cross-sectional data, available freely and publicly with all identifier information removed. Thus, for this data set, ethics approval was not required.

\section{Patient and public involvement}

This study did not involve patients or human subjects directly. The results of the analysis were exclusively based on the data from MICS Punjab, Pakistan.

\section{RESULTS}

Data was compiled for 24042 children under 5 years of age living in Punjab province of Pakistan. Table 1 demonstrates the demographic characteristics and factors associated with severe and moderate underweight in Punjab. The $\chi^{2}$ test for association of dependent variable, that is, underweight prevalence (moderate and severe), was assessed. All independent variables and corresponding $p$ values are reported in table 1 ( $p$ value $<0.05$ ). Prevalence of underweight was $33.3 \%$ as per the standard criteria of less than $-2 \mathrm{SD}(<-2 \mathrm{SD})$ between the reference median weight for age, and $11.25 \%$ were found to be severely underweight $(<-3 \mathrm{SD})$. Fifty-one perc ent of the study participants were boys, whereas one-third of the children were under 2 years of age at the time of the study. Majority (64\%) of the participants were of Punjabi ethnicity and one-fourth were of Sariki origin. Additionally, two-thirds (65\%) of the children were reported to be first-borns of their parents; however, the prevalence of underweight was found to be more in the 3-plus birth order children. Thirty-seven per cent of the babies were born with average birth weight and $11 \%$ were born with low birth weight. The percentage of underweight was found to be more $(45 \%)$ in low birthweight babies as compared with large and average (26\% and 32\%, respectively) birthweight babies. Out of the children who suffered from diarrhoea, $38 \%$ were reported to be moderately underweight and $15 \%$ were found to be severely underweight. More than half $(56 \%)$ of the mothers breast fed their babies, out of which a $34 \%$ were moderately underweight while $12 \%$ were severely underweight. Over half $(58 \%)$ of the mothers were between the age bracket of 25 and 35 years, out of which only $7 \%$ of the mothers had children when they were still less than 18 years old. A high prevalence of moderate $36 \%$ and $12 \%$ severe underweight was found in these children. Half of the mothers had no schooling, while $30 \%$ of the fathers had some schooling. Very few mothers $(7 \%)$ had a history of smoking. One-fourth of the mothers had a history of antennal visits of up to four times during their pregnancy, while one-fifth of the mothers were approached for postnatal care. Less than one-third of the mothers had delivered their babies at hospitals. Half of the mothers were found to be living in poor wealth status household. One-third of the respondents had more than eight members in their households. More than two-thirds of the children were found to be living in poor sanitary conditions. Majority of the children, however, had access to water, which was not treated and drinkable. Very few (15\%) families had access to daily newspapers and (5\%) had access to radios in their homes, while nearly two-thirds of the respondents had access to televisions. Nearly one-fifth of the children were visited by female health workers at their homes. Out of the total $69.6 \%$ children who belonged to rural areas in Punjab, 36\% were moderately underweight while $13 \%$ are severely underweight, whereas among the urban respondents from Punjab province, $27 \%$ were found to be moderately underweight and $7 \%$ were found to be severely underweight.

The results of multilevel multivariate models are presented in tables 2 and 3 as OR with a 95\% CI. Model 
Table 1 Prevalence of underweight (moderate and severe) in relation to demographic, socioeconomic, environmental and spatial characteristics in Punjab (MICS 2014)

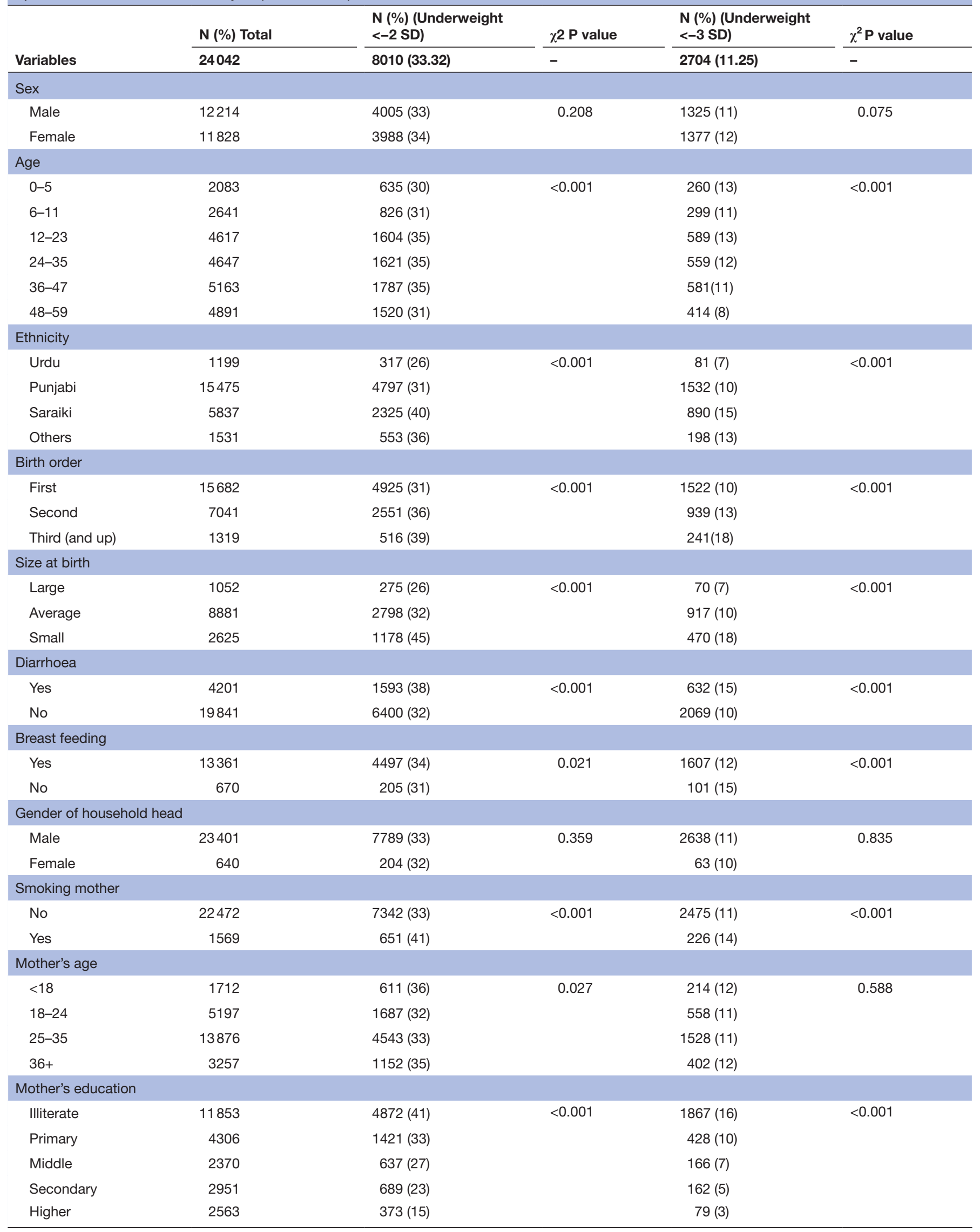


Table 1 Continued

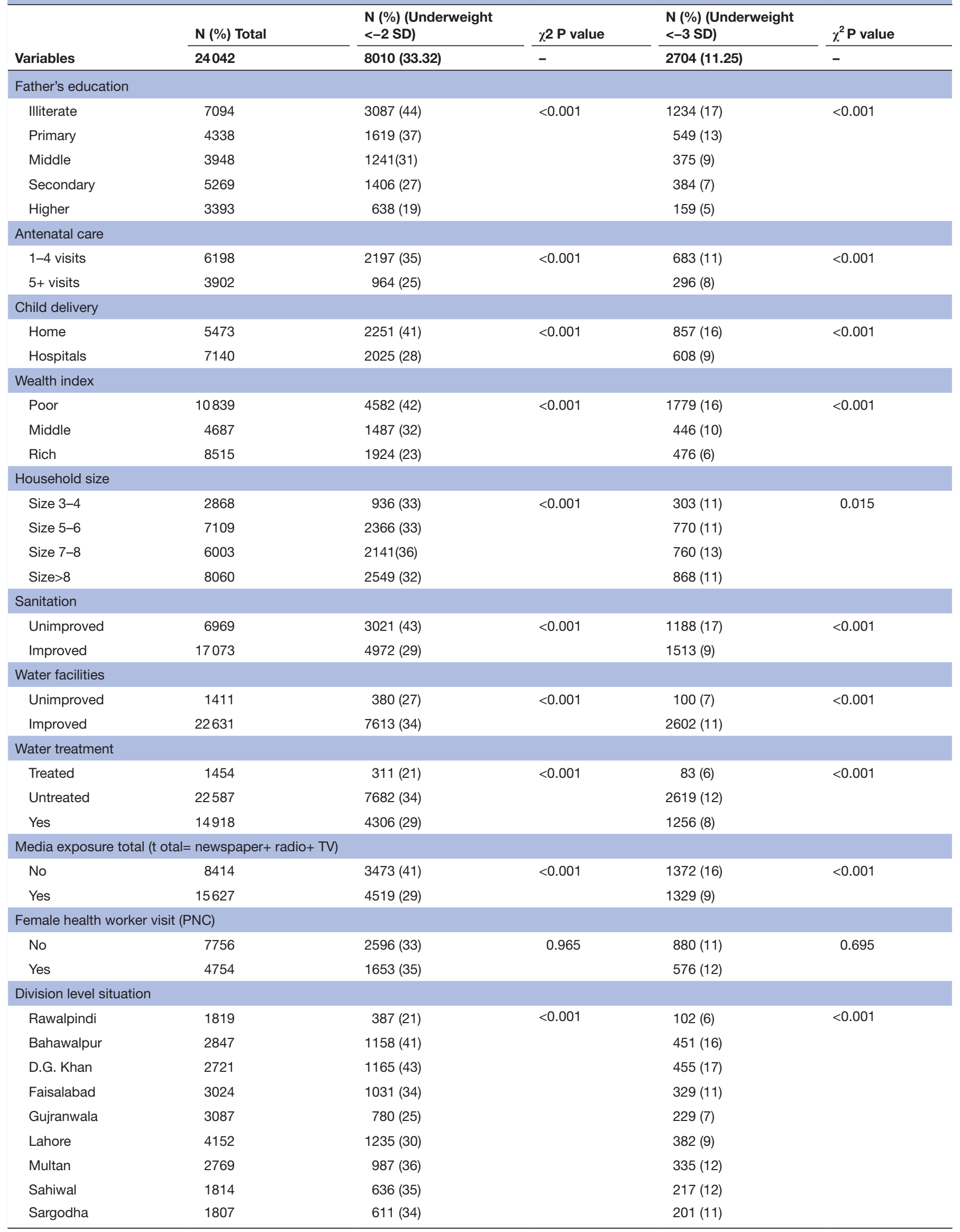


Table 1 Continued

\begin{tabular}{|c|c|c|c|c|c|}
\hline & N (\%) Total & $\begin{array}{l}\text { N (\%) (Underweight } \\
<-2 \text { SD) }\end{array}$ & $\chi 2$ P value & $\begin{array}{l}N(\%) \text { (Underweight } \\
<-3 \text { SD) }\end{array}$ & $\chi^{2} \mathbf{P}$ value \\
\hline Variables & 24042 & 8010 (33.32) & - & 2704 (11.25) & - \\
\hline Urban & 7447 & $2002(27)$ & $<0.001$ & $554(7)$ & $<0.001$ \\
\hline Rural & 16595 & $5991(36)$ & & 2147 (13) & \\
\hline
\end{tabular}

1 is an unconditional three-level hierarchical model that estimates the variation in underweight (moderate and severe) children without including any covariate and is used as a base model for comparison to check the explanatory power of the factors associated with underweight. Furthermore, model 2 includes child and parental characters, and model 3 includes household characteristics along with child, parental and regional characters (eg, administrative divisions). For example, compared with reference category of $0-5$ months, the odds of being underweight is almost $50 \%$ higher for children in the age bracket of 12-23 months (OR 1.46, 95\% CI 1.1 to 1.9 ), whereas for children between the ages of 36 and 47 months, the odds of being underweight is more than double (OR 2.54, 95\% CI 1.4 to 4.5 ) than that of the reference category of 0 to 5 months. Although the odds of being underweight for boys compared with girls is less (OR $0.92,95 \%$ CI 0.8 to 1.0 ), this difference is only significant at a $5 \%$ level of significance. Children with birth order 2 have higher odds of being underweight (OR 1.37, 95\% CI 1.2 to 1.5 ), whereas children with birth order of 3 or more are two times more likely to be stunted (OR 1.96, 95\% CI 1.5 to 2.5). Children with diarrhoea are significantly more likely to be underweight compared with those who have not had a single episode of diarrhoea (OR 1.31, 95\% CI 1.1 to 1.5). Children whose size at birth is perceived to be smaller than average are more than 2.7 times as likely to be moderately underweight than those who have an average or larger than average size at the time of birth (See table 2).

Compared with mothers with no education, children of highly educated mothers are significantly less likely to be moderately underweight (OR $0.31,95 \%$ CI 0.2 to 0.4 ), whereas children of mothers who have completed at least primary (OR $0.81,95 \%$ CI 0.7 to 0.9 ) or middle school (OR $0.62,95 \%$ CI 0.5 to 0.7 ) are significantly less likely than children of mothers with no education to be underweight. Children of fathers who have completed higher education are less likely to be underweight (OR $0.48,95 \%$ CI 0.4 to0.6). Children living in urban areas are less likely to be moderately underweight (OR $0.81,95 \%$ CI 0.7 to 0.9 ). Similarly, children who have access to improved sanitation facilities and households with higher income are significantly less likely to be moderately underweight. However, in this analysis, no significance was found between the delivery place of the child and breastfeeding practices. The results of severe underweight (less than $-3 \mathrm{SD}$ ) are presented in table 3 . The findings are in compliance with those of the moderately underweight with a similar magnitude and significance of coefficients. However, few exceptions do exist, for example, children who have not been breast fed are significantly more likely to be underweight. Similarly, children who were delivered at a hospital and those who have had media exposure are significantly less likely to be severely underweight. Household size, prenatal and postnatal care, smoking behaviour of mothers and drinking water facility were found to have no significant association with children being underweight in Punjab, Pakistan.

The results of VPC and ICC for both moderately and severely underweight children are shown in table 4 . The unconditional models only decompose the total outcome variance into level-specific variance components. In conditional models 2-3 (with explanatory variables), the VPC and ICC are based on the residual rather than observed outcomes. The unconditional model (model 1) for moderate underweight shows the variance at the district level and explains $3 \%(=0.16 / 5.75)$ proportional change in variance (VPC) of the total variance. The community-level variance shows $4 \%(=0.25 / 5.75)$ of the total variation, while the household level variation implies that the risk of underweight significantly varies across households by $36 \%(=2.06 / 5.75)$. Similarly, the results of the ICC statistics of moderate underweight (unconditional model 1) show that the district, community and household level ICC is $0.03,0.07$ and 0.43 , respectively. This implies that households living in the same community have higher chance of correlation of underweight than the households of adjacent communities. One can similarly explain other numbers of table 4 (eg, for severely underweight children).

\section{DISCUSSION}

This study used subnational-level multiple indicator cluster survey data (MICS 2014) from Punjab, Pakistan and analysed the factors associated with underweight children under the age of 5 using multilevel logistic regression models. The prevalence of underweight children was estimated to be 33\% in Punjab-this has remained unchanged since 2008. MICS data analyses reveal that the prevalence of underweight children in Punjab, Pakistan is higher than expected, especially when the high level of development and government spending in the province 
Table 2 Multilevel multivariable logistic regression results, Punjab (MICS 2014)

\section{Moderate underweight (>-2 SD)}

\begin{tabular}{|c|c|c|}
\hline Model 1† & $\begin{array}{l}\text { Model } 2 \ddagger \text { OR } \\
(95 \% \mathrm{Cl})\end{array}$ & $\begin{array}{l}\text { Model 3§ OR } \\
(95 \% \mathrm{Cl})\end{array}$ \\
\hline \multicolumn{3}{|l|}{ Child age group (reference category $0-5$ months) } \\
\hline $12-23$ & $1.46^{\star \star}(1.1$ to 1.9$)$ & $1.48^{\star \star}(1.1$ to 1.9$)$ \\
\hline 24-35 & $1.70^{\star \star}(1.2$ to 2.5$)$ & $1.69^{* *}(1.2$ to 2.5$)$ \\
\hline $36-47$ & $2.54^{\star \star}(1.4$ to 4.5$)$ & $2.59^{\star \star}(1.5$ to 4.6$)$ \\
\hline \multicolumn{3}{|l|}{ Child gender (reference category Girls) } \\
\hline Boys & $0.92^{\star \star}(0.8$ to 1.0$)$ & $0.92^{* \star}(0.8$ to 1.0$)$ \\
\hline \multicolumn{3}{|l|}{ Child birth order (reference category First born) } \\
\hline 2 & $1.37^{\star \star \star}(1.2$ to 1.5$)$ & $1.37^{\star \star \star}(1.2$ to 1.5$)$ \\
\hline Small & $2.77^{\star \star \star}(2.2$ to 3.5$)$ & $2.70^{\star \star \star}(2.1$ to 3.5$)$ \\
\hline \multicolumn{3}{|l|}{ Diarrhoea (reference category No) } \\
\hline Yes & $1.31^{\star \star *}(1.1$ to 1.5$)$ & $1.29^{\star \star \star}(1.1$ to 1.5$)$ \\
\hline \multicolumn{3}{|l|}{ Breast feeding (reference category Yes) } \\
\hline No & $0.92(0.7$ to 1.2$)$ & 0.93 (0.7 to 1.2$)$ \\
\hline \multicolumn{3}{|l|}{ Household sex (reference category Female) } \\
\hline Male & $0.83(0.6$ to 1.1$)$ & $0.81(0.6$ to 1.0$)$ \\
\hline \multicolumn{3}{|c|}{ Mother's education (reference category No education) } \\
\hline Primary & $0.81^{\star \star \star}(0.7$ to 0.9$)$ & $0.90^{\star *}(0.8$ to 1.0$)$ \\
\hline $36-49$ & 0.94 (0.8 to 1.1$)$ & 0.91 (0.7 to 1.1$)$ \\
\hline \multicolumn{3}{|l|}{ Prenatal care (reference category 1-4 visits) } \\
\hline More than four visits & 0.87 (0.8 to 1.0$)$ & $0.92(0.8$ to 1.1$)$ \\
\hline \multicolumn{3}{|c|}{ Postnatal care to female health worker visit (reference category Yes) } \\
\hline No & 0.93 (0.8 to 1.0$)$ & 0.90 (0.8 to 1.0$)$ \\
\hline \multicolumn{3}{|l|}{ Delivery place (reference category Home) } \\
\hline Hospital & $0.85^{\star \star}(0.7$ to 1.0$)$ & 0.89 (0.8 to 1.0$)$ \\
\hline \multicolumn{3}{|l|}{ Mother smokes (reference category No) } \\
\hline Yes & 1.17 (1.0 to 1.4$)$ & 1.11 (0.9 to 1.3$)$ \\
\hline \multicolumn{3}{|l|}{ Father's education (reference category No education) } \\
\hline Primary & $0.89(0.8$ to 1.0$)$ & $0.94(0.8$ to 1.1$)$ \\
\hline Middle & $0.72^{\star \star \star}(0.6$ to 0.8$)$ & $0.79^{\star \star}(0.7$ to 0.9$)$ \\
\hline Secondary & $0.58^{\star \star \star}(0.5$ to 0.7$)$ & $0.66^{\star \star \star}(0.6$ to 0.7$)$ \\
\hline Higher & $0.48^{\star \star \star}(0.4$ to 0.6$)$ & $0.55^{\star \star \star}(0.4$ to 0.7$)$ \\
\hline \multicolumn{3}{|l|}{ Wealth index (reference category Poor) } \\
\hline Middle & & $0.81^{\star *}(0.7$ to 0.9$)$ \\
\hline Rich & & $0.63^{\star \star \star}(0.5$ to 0.7$)$ \\
\hline
\end{tabular}


Table 2 Continued

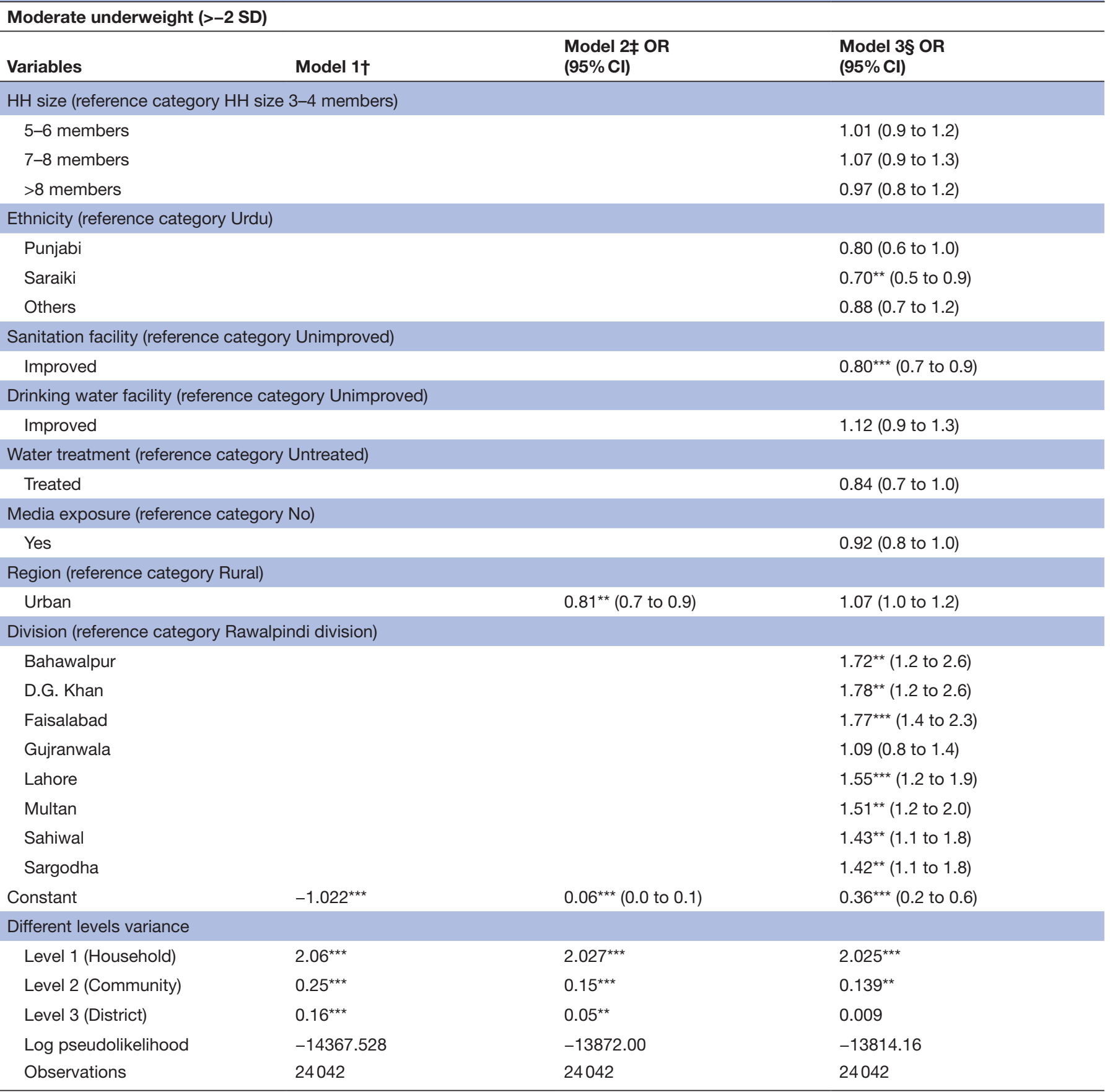

${ }^{*} \mathrm{P}<0.05 ;{ }^{* \star} \mathrm{p}<0.01 ;{ }^{* \star *} \mathrm{p}<0.001$.

†Base model (unconditional three level hierarchical model).

†Hierarchical model with child and parental characteristics.

$\S$ Hierarchical model with child, parental, household and division.

is taken into account. These figures are higher even than those of neighbouring countries including Afghanistan and Nepal, ${ }^{1325}$ and are only slightly less than those of India and Bangladesh. ${ }^{72627}$ Furthermore, this study, using multilevel logistic regression model, estimated the factors associated with the prevalence of moderate and severe underweight. Maternal and household risk factors included low education levels, smoking history, antenatal care visits, not having the delivery assisted by a health professional, access to safe drinking water, sanitation, bigger household size, living area and poor wealth index. Regional studies show that income, mother's educational level and access to safe drinking water are the main factors which lead to children being underweight. ${ }^{28-30}$

Children suffering from diarrhoea were significantly more likely to be moderately and severely underweight compared with the children who had not suffered from an episode of diarrhoea in the 2 weeks prior to the survey. 
Table 3 Multivariable regression results of multilevel models Punjab (MICS 2014)

\section{Severe underweight (> -3SD)}

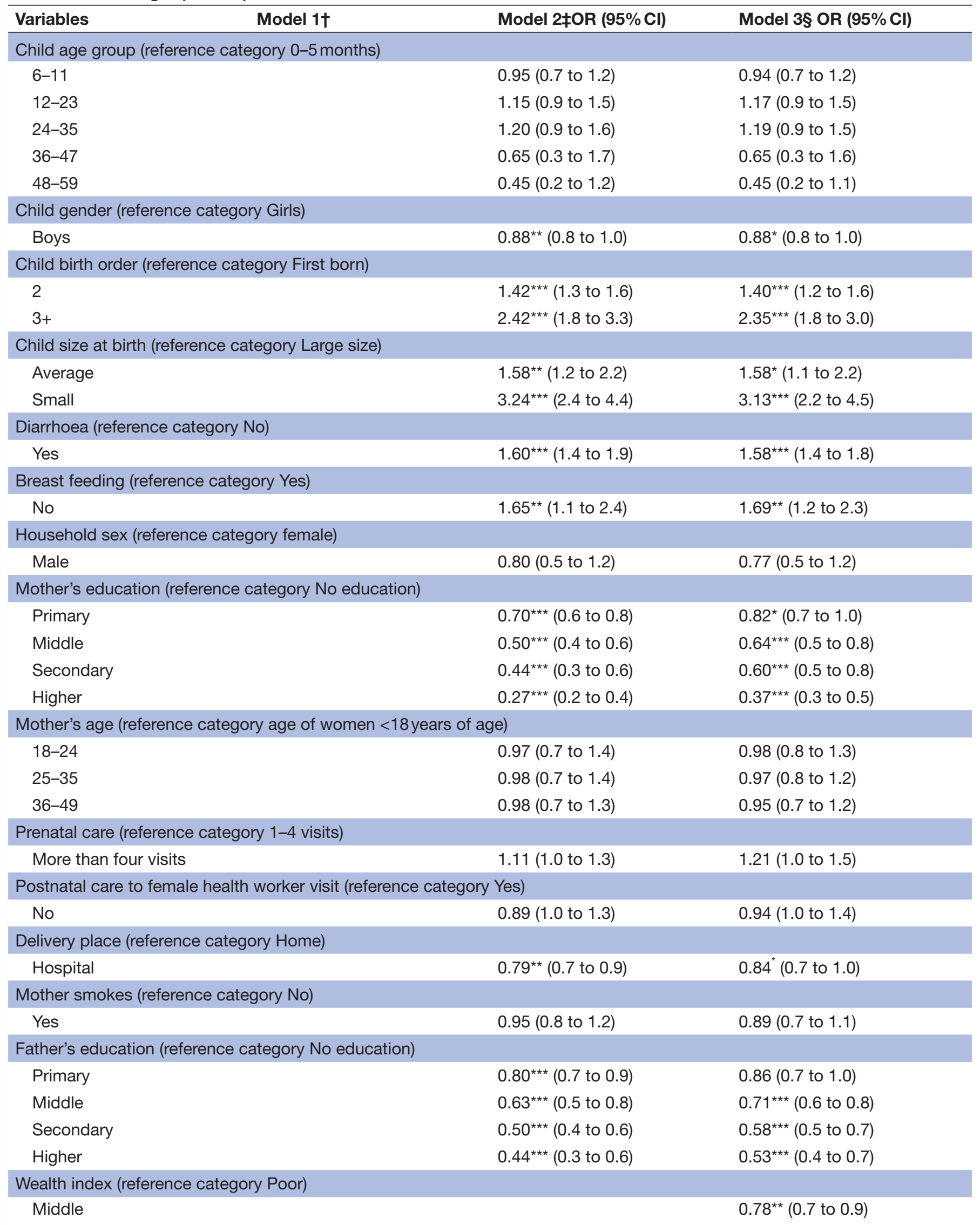


Table 3 Continued

Severe underweight $(>-3 S D)$

\begin{tabular}{|c|c|c|c|}
\hline Variables & Model 1† & Model 2‡OR $(95 \% \mathrm{Cl})$ & Model $3 \S$ OR $(95 \% \mathrm{Cl})$ \\
\hline Rich & & & $0.59^{4+* t}(0.5$ to 0.7$)$ \\
\hline \multicolumn{4}{|c|}{ HH size (reference category HH size 3-4 members) } \\
\hline 5-6 members & & & 1.05 (0.9 to 1.3$)$ \\
\hline 7-8 members & & & $1.17(1.0$ to 1.4$)$ \\
\hline$>8$ members & & & 1.07 (0.9 to 1.3$)$ \\
\hline \multicolumn{4}{|c|}{ Ethnicity (Reference category Urdu) } \\
\hline Punjabi & & & 0.88 (0.6 to 1.2$)$ \\
\hline Saraikai & & & 0.82 (0.6 to 1.2$)$ \\
\hline Others & & & 0.90 (0.6 to 1.3$)$ \\
\hline \multicolumn{4}{|c|}{ Sanitation facility (reference category Unimproved) } \\
\hline Improved & & & $0.83^{\star \star}(0.7$ to 0.9$)$ \\
\hline \multicolumn{4}{|c|}{ Drinking water facility (reference category Unimproved) } \\
\hline Improved & & & 1.20 (0.9 to 1.6$)$ \\
\hline \multicolumn{4}{|c|}{ Water treatment (reference category Untreated) } \\
\hline Treated & & & $0.80(0.6$ to 1.1$)$ \\
\hline \multicolumn{4}{|c|}{ Media exposure (reference category No) } \\
\hline Yes & & & $0.82^{* \star}(0.7$ to 0.9$)$ \\
\hline \multicolumn{4}{|c|}{ Region (reference category Rural) } \\
\hline Urban & & $0.91^{*}(0.8$ to 1.0$)$ & 1.04 (0.9 to 1.2$)$ \\
\hline \multicolumn{4}{|c|}{ Division (reference category Rawalpindi division) } \\
\hline Bahawalpur & & & $1.72^{\star *}(1.2$ to 2.4$)$ \\
\hline D.G. Khan & & & $1.74^{\star \star}(1.2$ to 2.4$)$ \\
\hline Faisalabad & & & $1.71^{\star \star \star}(1.2$ to 2.4$)$ \\
\hline Gujranwala & & & 1.17 (0.9 to 1.6$)$ \\
\hline Lahore & & & $1.54^{\star \star}(1.1$ to 2.1$)$ \\
\hline Multan & & & $1.47^{\star}(1.1$ to 2.1$)$ \\
\hline Sahiwal & & & $1.43^{*}(1.0$ to 2.0$)$ \\
\hline Sargodha & & & $1.45^{\star}(1.0$ to 2.1$)$ \\
\hline Constant & $-2.85^{\star \star \star}$ & $0.36^{\star \star \star}(0.2$ to 0.5$)$ & $0.05^{*+*}(0.0$ to 0.1$)$ \\
\hline \multicolumn{4}{|l|}{ Variation at different levels } \\
\hline Level 1 (Household) & $1.949^{\star \star \star}$ & $1.961^{\star \star *}$ & $1.949^{\star \star *}$ \\
\hline Level 2 (Community) & $0.278^{\star \star \star}$ & $0.188^{\star \star \star}$ & $0.165^{\star \star}$ \\
\hline Level 3 (District) & $0.161^{\star \star}$ & $0.022^{*}$ & 0.009 \\
\hline Log pseudolikelihood & -8067.020 & -13872.00 & -7610.8 \\
\hline Observations & 24042 & 24042 & 24042 \\
\hline
\end{tabular}

${ }^{*} \mathrm{P}<0.05 ;{ }^{* *} \mathrm{p}<0.01 ;{ }^{* * *} ;<0.001$.

†Base model (unconditional three level hierarchical model).

¥Hierarchical model with child and parental characteristics.

$\S$ Hierarchical model with child, parental, household and division.

Diarrhoea results in dehydration and a loss of appetite; these factors lead to adverse child health outcomes such as underweight. This finding is supported by a study from Bangladesh, which shows that diarrhoea during childhood has a significant effect on undernutrition. ${ }^{7}$ Another study revealed that wasting results in chronic illness and infections like diarrhoea. ${ }^{31}$ Another study from Nepal suggests that safe drinking water prevents diarrhoea, which ultimately leads to a reduction in childhood underweight. ${ }^{13}$ Underweight in children increases the chances of developing other infections due to their low immunity against infectious agents. ${ }^{32}$ On the other hand, high 
Table 4 Results from random intercept model: measure of variation VPC and ICC

\begin{tabular}{|c|c|c|c|c|c|c|}
\hline \multirow{2}{*}{$\begin{array}{l}\text { Models } \\
\text { SD }\end{array}$} & \multicolumn{2}{|c|}{ Model 1} & \multicolumn{2}{|c|}{ Model 2} & \multicolumn{2}{|c|}{ Model 3} \\
\hline & -2 SD & -3 SD & $-2 S D$ & $-3 S D$ & -2 SD & $-3 S D$ \\
\hline \multicolumn{7}{|c|}{ Variance partition coefficient (VPC) } \\
\hline VPC & 0.04 & 0.05 & 0.03 & 0.03 & 0.03 & 0.03 \\
\hline $\mathrm{VPC}_{\mathrm{hh}}$ & 0.36 & 0.34 & 0.37 & 0.36 & 0.37 & 0.36 \\
\hline $\mathrm{ICC}_{\mathrm{distt}}$ & 0.03 & 0.03 & 0.009 & 0.004 & 0.002 & 0.002 \\
\hline $\mathrm{ICC}_{\text {comm }}$ & 0.07 & 0.08 & 0.039 & 0.034 & 0.032 & 0.032 \\
\hline $\mathrm{ICC}_{\mathrm{hh}}$ & 0.43 & 0.42 & 0.409 & 0.394 & 0.402 & 0.392 \\
\hline
\end{tabular}

metabolic demand for infection can result in weight loss among babies due to reduced food absorption and loss of appetite. ${ }^{10}$ Community interventions, including provision of nutrients, have a positive impact on the child's health, which ultimately helps prevent infections and improve their immunity. ${ }^{33-36}$ The size of the child at time of birth was significantly associated with their nutritional status. Children who were of a size smaller than average at birth were more prone to underweight as compared with children who were of an average or larger than average size at birth. These findings are consistent with previous studies. 303738

Our study shows that mother's education was correlated with dietary status among children under 5 years of age and showed a lack of relationship between prenatal/ postnatalcare and underweight. Mother's education has a positive affect on the child's health and leads to positive health seeking behaviour with mothers paying more attention to antenatal and postnatal checkups. Educated mothers could manage households in a better way and provide a more nutritious diet to their children. These findings are similar to previous researches conducted in Bangladesh, which confirmed that underweight was associated with lower parental education. ${ }^{7}$ The study also shows a strong association between institutional delivery and mother's education, which in turn affects child health. ${ }^{39}$ Female education status is very low in Pakistan which might be a contributing factor towards the high burden of underweight in children. ${ }^{28}$ Research suggests that 10 years of education or more among mothers can lead to the reversal of almost half of the malnutrition burden among children in high prevalent areas of the developing world. ${ }^{8}$ Educated mothers are well informed about the ways to provide care to their children and show positive practices with regard to health and hygiene, breast feeding and empowered decision making in health. ${ }^{1235}$ Smoking behaviours in mothers, in our study, were not significantly associated with underweight, this may be due to the small number of smoking mothers in the sample.

Place of delivery highly impacts the weight of children according to this study. Children born at home are significantly more likely to be underweight as compared with those delivered at a health facility. These results are in line with studies from Bangladesh, India and Nepal. ${ }^{264041}$ It can be inferred that giving birth at home is mostly preferred by uneducated mothers ${ }^{42}$; women with low levels of education do not have awareness and are not empowered to make decisions about the best care they can provide for their child. In most cases, these mothers are also unaware about the benefits of institutional delivery and the harmful impacts of not getting proper postnatal care offered by hospitals which can affect the nutrition that their child gets and they miss out on early healthcare advantages that help in better child health outcomes. ${ }^{38}$ Underweight among children is reported high among families that have more than three children. Repeated pregnancies are a significant cause of poor health among mothers, as also shown by previous studies. It had also previously been found that multiple childbirths adversely impact mother and child's health. ${ }^{38} 43$

Parents of children in this survey who had access to media (television, radio and newspaper) reported low underweight in their babies. These results indicate that these parents were aware of the latest trends and practices to ensure provision of proper nutrition to their children. Our results are consistent with similar findings in studies conducted in Nigeria and Bangladesh that show the helpful link between the use of media and underweight. ${ }^{3844}$ This study shows that families of children that live in rural areas were more underweight as compared with those living in urban areas. This could be due to the poor health infrastructure and lack of availability of healthcare professionals and lack of equipment available in rural health facilities. ${ }^{12}$ Unsafe drinking water, poor sanitation, improper housing and low literacy in the area would positively affect nutrition of children and health of people. This imbalance in the resources would make their children more vulnerable to infections and illnesses that ultimately cause underweight. These findings are consistent with a study conducted in Congo, which shows that there were more underweight babies in rural areas as compared with urban centres. ${ }^{44}$ In this study, breast feeding, household size and prenatal and postnatal care have no significant effect on children's health status. 
However, our study does have some limitations. First, the analyses are based on cross-section data and hence we cannot conclude any causal relationship among factors associated with moderate and severe underweight. Second, even though this study has been conducted across the largest province of Pakistan, the results of the study cannot be generalised at the country level. Nevertheless, the results can be helpful in understanding the dynamics of the factors associated with underweight in the province and can provide a substantial guideline and starting point for better policy formulation and interventions.

\section{CONCLUSION}

Based on our findings, a rigorous community-based intervention should be developed and executed throughout the province to improve the grave situation of underweight prevalence. Mother's education should be uplifted by providing formal education and awareness about nutrition. Health system access for underprivileged and poor households could be improved by providing proper health facilities in rural areas. Proper family planning and gap between subsequent child births should be maintained to achieve better health for both the mother and the child. Hence, it is recommended that the policy makers should focus on these interventions to improve the nutritional status among children under the age of 5 in Pakistan.

Acknowledgements This research is supported by Rachadapisek Sompote Fund for Postdoctoral Fellowship, Chulalongkorn University Thailand. Dr. Faisal Abbas acknowledges the receipt of the fellowship provided by Alexander Von Humboldt Foundation, Germany. Dr. Tahir acknowledges the receipt of faculty development fund (FDF) provided by Higher Education Commission (HEC) Islamabad, Pakistan.

Contributors FA and RK performed the literature search and conceptualised this study. Data analysis was done by TM with input from FA as well as interpretation of multilevel results. The manuscript was drafted by RK and FA and reviewed by FA, RS and TM. All the authors were involved in revision and editing of the draft. All authors critically reviewed the final manuscript and approve the draft for final submission.

Funding The authors have not declared a specific grant for this research from any funding agency in the public, commercial or not-for-profit sectors.

Competing interests None declared.

Patient consent for publication Not required.

Ethics approval None.

Provenance and peer review Not commissioned; externally peer reviewed.

Data sharing statement MICS data set is publically available online on the following link: http://mics.unicef.org/surveys.

Open access This is an open access article distributed in accordance with the Creative Commons Attribution Non Commercial (CC BY-NC 4.0) license, which permits others to distribute, remix, adapt, build upon this work non-commercially, and license their derivative works on different terms, provided the original work is properly cited, appropriate credit is given, any changes made indicated, and the use is non-commercial. See: http://creativecommons.org/licenses/by-nc/4.0/.

\section{REFERENCES}

1. The United Nations Children's Fund. World Health Organization. World Bank. UNICEF. WHO-The World Bank Child Malnutrition Database: Estimates for 2015 and Launch of Interactive Data Dashboards. New York: The United Nations Children's Fund, 2015.
2. Bhutta ZA, Soofi SB, Zaidi SSH, et al. Pakistan National Nutrition Survey, 2011, 2011.

3. Khan S, Zaheer S, Safdar NF. Determinants of stunting, underweight and wasting among children <5years of age: evidence from 20122013 Pakistan demographic and health survey. BMC Public Health 2019;19:358.

4. United Nations International Children Emergency Fund (UNICEF). Multi Indicater Cluster Survey (MICS). Provincial report. Punjab: UNICEF, Planning Department, Government of Pakistan, 2014.

5. Bhutta ZA, Hafeez A, Rizvi A, et al. Reproductive, maternal, newborn, and child health in Pakistan: challenges and opportunities. Lancet 2013;381:2207-18.

6. Asim M, Nawaz Y. Child Malnutrition in Pakistan: Evidence from Literature. Children 2018;5:60.

7. Chowdhury TR, Chakrabarty S, Rakib M, et al. Socio-economic risk factors for early childhood underweight in Bangladesh. Global Health 2018;14:54.

8. Müller O, Krawinkel M. Malnutrition and health in developing countries. CMAJ 2005;173:279-86.

9. Black RE, Victora CG, Walker SP, et al. Maternal and child undernutrition and overweight in low-income and middle-income countries. Lancet 2013;382:427-51.

10. Nigatu G, Assefa Woreta S, Akalu TY, et al. Prevalence and associated factors of underweight among children 6-59 months of age in Takusa district, Northwest Ethiopia. Int J Equity Health 2018;17:106

11. Ghosh-Jerath $\mathrm{S}$, Singh $\mathrm{A}$, Jerath $\mathrm{N}$, et al. Undernutrition and severe acute malnutrition in children. BMJ 2017;359:j4877.

12. Sand A, Kumar R, Shaikh BT, et al. Determinants of severe acute malnutrition among children under five years in a rural remote setting: A hospital based study from district Tharparkar-Sindh, Pakistan. Pak $J$ Med Sci 2018;34:260-5.

13. Guerrant RL, DeBoer MD, Moore SR, et al. The impoverished gut--a triple burden of diarrhoea, stunting and chronic disease. Nat Rev Gastroenterol Hepatol 2013;10:220-9.

14. Adhikari D, Khatri RB, Paudel YR, et al. Factors Associated with Underweight among Under-Five Children in Eastern Nepal: Community-Based Cross-sectional Study. Front Public Health 2017;5:350.

15. Ezzati M, Lopez AD, Rodgers A, et al. Comparative Risk Assessment Collaborating G. Selected major risk factors and global and regional burden of disease. Lancet 2002;360:1347-60.

16. Fikree FF, Rahbar MH, Berendes HW. Risk factors for stunting and wasting at age six, twelve and twenty-four months for squatter children of Karachi, Pakistan. J Pak Med Assoc 2000;50:341-8.

17. Baig-Ansari N, Rahbar MH, Bhutta ZA, et al. Child's gender and household food insecurity are associated with stunting among young Pakistani children residing in urban squatter settlements. Food Nutr Bull 2006;27:114-27.

18. Anwer I, Awan JA. Nutritional status comparison of rural with urban school children in Faisalabad District, Pakistan. Rural Remote Health 2003;3:130.

19. Shah SM, Selwyn BJ, Luby S, et al. Prevalence and correlates of stunting among children in rural Pakistan. Pediatr Int 2003;45:49-53.

20. Khuwaja S, Selwyn BJ, Shah SM. Prevalence and correlates of stunting among primary school children in rural areas of southern Pakistan. J Trop Pediatr 2005;51:72-7.

21. World Health Organization (WHO). Global Database on Child Growth and Malnutrition. 2018 https://www.who.int/nutgrowthdb/en/ (cited 2018, 30 October).

22. World Health Organization (WHO). Water sanitation hygiene,. 2018 http://www.who.int/water_sanitation_health/monitoring/jmp2012/ key_terms/en/ (cited 30 Oct 2018).

23. Kreft GI, Leeuw DJ. Introducing Multilevel Modeling: Sage Publications, 1998.

24. Snijders TAB, Bosker RJ. Multilevel Analysis: An Introduction to Basic and Advanced Multilevel Modeling. London: Sage Publications, 1999.

25. Frozanfar MK, Yoshida Y, Yamamoto E, et al. Acute malnutrition among under-five children in Faryab, Afghanistan: prevalence and causes. Nagoya J Med Sci 2016;78:41-53.

26. Ahmed T, Mahfuz M, Ireen S, et al. Nutrition of children and women in Bangladesh: trends and directions for the future. $J$ Health Popul Nutr 2012;30:1-11.

27. Ambadekar NN, Zodpey SP. Risk factors for severe acute malnutrition in under-five children: a case-control study in a rural part of India. Public Health 2017;142:136-43.

28. Cheema A, Khalid L, Patnam M. The Geography of Poverty: Evidence from the Punjab. The Lahore Journal of Economics 2008;13:163-83.

29. SDPI/SDC/WFP. Food insecurity in Pakistan, 2009. 
30. World Bank (WB). Prevalence of underweight, weight for age (\% of children under 5). 2018 https://data.worldbank.org/indicator/sh.sta. maln.zs.

31. Asfaw M, Wondaferash $\mathrm{M}$, Taha $\mathrm{M}$, et al. Prevalence of undernutrition and associated factors among children aged between six to fifty nine months in Bule Hora district, South Ethiopia. BMC Public Health 2015;15:41.

32. Dewey KG, Mayers DR. Early child growth: how do nutrition and infection interact? Matern Child Nutr 2011;7 Suppl 3(Suppl 3):129-42.

33. Bhutta ZA, Ahmed T, Black RE, et al. What works? Interventions for maternal and child undernutrition and survival. Lancet 2008;371:417-40.

34. Vaivada T, Gaffey MF, Das JK, et al. Evidence-based interventions for improvement of maternal and child nutrition in lowincome settings: what's new? Curr Opin Clin Nutr Metab Care 2017;20:204-10.

35. Bhutta ZA, Das JK, Rizvi A, et al. Evidence-based interventions for improvement of maternal and child nutrition: what can be done and at what cost? Lancet 2013;382:452-77.

36. Chawla N, Panza A, Sirikulchayanonta C, et al. Effectiveness of a school-based multicomponent intervention on nutritional status among primary school children in bangkok, Thailand. J Ayub Med Coll Abbottabad 2017;29:13-20.
37. Hasnain SF, Hashmi SK. Consanguinity among the risk factors for underweight in children under five: a study from rural Sindh. J Ayub Med Coll Abbottabad 2009;21:111-6.

38. Akombi BJ, Agho KE, Merom D, et al. Multilevel Analysis of Factors Associated with Wasting and Underweight among Children UnderFive Years in Nigeria. Nutrients 2017;9.

39. Semba RD, de Pee S, Sun K, et al. Effect of parental formal education on risk of child stunting in Indonesia and Bangladesh: a cross-sectional study. Lancet 2008;371:322-8.

40. Pardeshi GS, Dalvi SS, Pergulwar CR, et al. Trends in choosing place of delivery and assistance during delivery in Nanded district, Maharashtra, India. J Health Popul Nutr 2011;29:71-6.

41. Shrestha SK, Banu B, Khanom K, et al. Changing trends on the place of delivery: why do Nepali women give birth at home? Reprod Health 2012;9:25.

42. Parveen Z, Sadiq M, Abbas F, et al. Correlates of home and hospital delivery in Pakistan. J Pak Med Assoc 2017;67:1166-72.

43. Cristina Rossi A. Underweight and pregnancy. BJOG 2016;123:2008

44. Rahman A, Chowdhury S, Hossain D. Acute malnutrition in Bangladeshi children: levels and determinants. Asia Pac J Public Health 2009;21:294-302.

45. Kandala NB, Madungu TP, Emina JB, et al. Malnutrition among children under the age of five in the Democratic Republic of Congo (DRC): does geographic location matter? BMC Public Health 2011;11:261. 